\title{
The expiry date of man: a synthesis of evolutionary biology and public health
}

\author{
Luc Bonneux, Jan J Barendregt, Paul J Van der Maas
}

\begin{abstract}
In industrialised countries, mortality and morbidity are dominated by age related chronic degenerative diseases. The health and health care needs of future populations will be heavily determined by these conditions of old age. Two opposite scenarios of future morbidity exist: morbidity might decrease ("compress"), because life span is limited, and the incidence of disease is postponed. Or morbidity might increase ("expand"), because death is delayed more than disease incidence. Optimality theory in evolutionary biology explains senescence as a by product of an optimised life history. The theory clarifies how senescence is timed by the competing needs for reproduction and survival, and why this leads to a generalised deterioration of many functions at many levels. As death and disease are not independent, future morbidity will depend on duration and severity of the process of senescence, partly determined by health care, palliating the disease severity but increasing the disease duration by postponing death. Even if morbidity might be compressed, health care needs will surely expand. (F Epidemiol Community Health 1998;52:619-623)
\end{abstract}

In this article, we discuss expectations of future mortality, morbidity, and health care costs in developed countries with high levels of health and health care. The use of such expectations include estimating future demands for health care, identifying the types of services to be provided (for example, hospital care, nursing care, or other types of institutional care) and determining the prevalence and range of disabilities that exist in a population, to mention a few. ${ }^{1}$ Examples abound of the uses of forecasts of the size and health status of the population for health policy planning. Particularly the expected increases in chronic conditions of old age such as dementia, hip fractures, or heart failure are a matter of concern..$^{2-4}$ The projected growth of the elderly population, those aged 75 and older, caused both by high birth rates in the past and increased survival now and in the future is the main determinant of escalating needs for long term care. ${ }^{3}$ As nearly all future residents of nursing homes and sufferers from disabling diseases of old age between now and 2060 have already been born, forecasts of the size of the health care needs of the elderly population rely heavily on estimates of future survival, and the health status of those surviving. Such long term forecasts of future morbidity and mortality are to be based on an understanding of age related disorders. Why does aging, or better senescing, happen?

The hallmark of senescence is the progressive increase in age specific death rates following puberty, observed in all mammals and many other species kept under conditions ideal for survival. ${ }^{6-8}$ Underlying this progressive increase is a generalised deterioration in a broad spectrum of physiological and metabolical functions. ${ }^{910}$ These physiological decrements leave the organism increasingly vulnerable to a variety of intrinsic and extrinsic factors that may cause disease, disability, and death. The evolutionary theory of aging explains senescence as a process tailored by natural selection in evolutionary time.

In this paper we will first explain the fundamentals of evolutionary theory. Then we discuss consequences for future public health.

\section{A history of life and death}

Neo-Darwinian evolutionary theory states that the human genome is the result of the forces of natural selection through evolutionary time scales. ${ }^{11}$ The evolutionary success of a species is determined by the "fitness" of its individuals, the increase or decrease of numbers of descendants through successive generations. $^{1213}$

"GENETIC NEGLECT"

Figure 1 shows the mortality history of Dutch men and women in the 20th century. While the life expectancy increased tremendously, the age dependent mortality changes are remarkably similar in all periods. ${ }^{5}$ Child mortality is highest immediately after conception, and decreases to low levels at the end of childhood and the beginning of puberty. Even in the darkest of ages and the harshest of conditions, all our forefathers and foremothers succeeded to reach adulthood and have at least one child. Not a single one in our long line of ancestors died in infancy or childhood. Genes commanding juvenile survival must be very good indeed. ${ }^{14}$

But after the onset of puberty the cumulative probability of both successful reproduction and (violent) death is increasing. In natural conditions the mortality hazard is high, and relatively constant over age. The probability that a person would be dead-from hunger, injury, infection or predation-increases sharply by age, long before old age is reached. The power of natural selection, weeding out detrimental mutations, is consequently decreasing. Genes protecting survival at older ages are not selected for, because aging is rare, and 

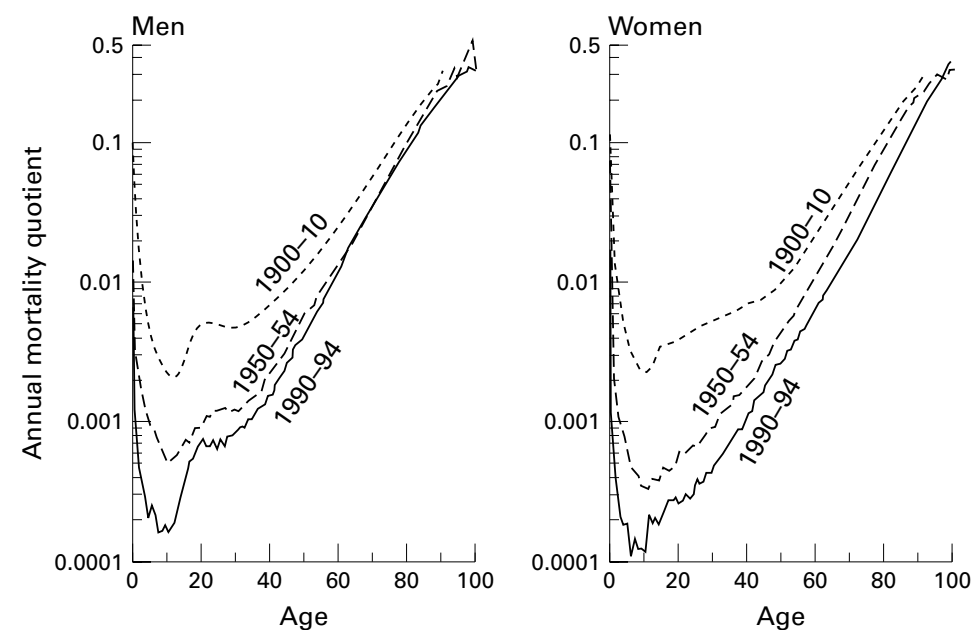

Figure 1 Death rates by sex, age, and three time periods in the 20th century.

inconsequential to production and survival of offspring. ${ }^{6}$ Evolution does not care about elderly.

This is the central pillar of any evolutionary theory of aging: with or without senescence, the length of life is limited. ${ }^{6}{ }^{15}{ }^{16}$ In natural conditions mortality from hunger, injury, infection or predation is so high, that few individuals survive into old age.

\section{A BODY IS A DISPOSABLE GOOD}

There is an additional reason why senescence exists. Millions of years of ruthless competition have optimised the life history of a species. ${ }^{16-18}$ Food (energy) is nearly always in short supply. Given similar physiologies and environmental constraints, the organism that makes the most of scarce resources, will have the stronger lineage of successful descendants. There are choices to be made between investing resources in reproduction or survival. ${ }^{9} 5^{15} 16$

Some species invest in much offspring early in life, but at the price of high mortality and short life spans. Others adopt a caring strategy: they live long, but reproduce late and little. Homo sapiens is the ultimate carer among mammals. His very long life span is related to his very long youth, which again is related to the large size of his brains. ${ }^{71}{ }^{20}$ The larger the brain is, the longer education and parental care is needed to make use of its full potential. ${ }^{7}$ But after the offspring is able to fend for himself, the parent is disposable from the point of view of natural selection.

The alternative name of the optimality theory of senescence, the "disposable soma" theory, refers to the disposable goods from economy. ${ }^{916}$ An optimal product takes into account the expected duration of use of that product. It is a waste of resources to invest in increased durability beyond that duration. For animals that is the natural life expectancy in the wild. ${ }^{21}$ Organisms who succeed in diverting this energy to more successful reproduction will outcompete the more wasteful. Fitness - that is, successful offspring - not survivorship, determines evolutionary success.

Optimality theory is consistent with other, non-evolutionary, theories of aging. The evolu- tion theory gives an "ultimate" explanation, why stochastic "wear and tear" and/or somatic damage such as oxidative stress by free radicals cause senescence. ${ }^{21-23}$ Lasting damage is not inevitable: living beings are dynamic systems, capable of maintenance and repair. Damage happens because maintenance and repair become increasingly less effective at older ages, when the body is disposable.

\section{THEORIES OF ADAPTATION}

The previous explanations of senescence are called non-adaptive. Animals are not selected "because" they senesce. Senescence is a by product of lack of selection pressure and an optimal life history. Alternative theories state that senescence can be adaptive; they are based on an argument of crowding. "Groups" are selected for senescence, because the older individuals are discarded, and leave room for the healthy young. Firstly, there is a circularity in this argument: the reason why the old are unhealthy and subfertile is because they senesce. Next, if the circularity is excluded by stating that the old are as healthy and as fertile as the young, it is hard to see how these groups might be disadvantaged, compared with groups with unhealthy elderly.

Based on theories of adaptation the existence of "suicide genes" can be predicted, genes that actively programme the end of life. This is unlikely for the same reason: there would be strong selection pressure for mutations deleting these genes. At least in the short-term, these immortal (healthy and fertile) "escape mutants" would outcompete the aging mortals in numbers of offspring. Such escape mutants have never been observed in nature.

\section{Disability and death from evolutionary perspective}

Optimality theory states that the age dependent occurrence of degenerative diseases is timed by the life history of our ancestors. Energy consuming maintenance systems at multiple levels, from subcellular DNA-repair to normal functioning of the brain, will assure more or less the same life span. ${ }^{8-10}$ This implies that diseases caused by senescence are timed by the same process. The distinction between fatal and disabling conditions only makes sense in human societies: in natural conditions, a disabled hunter has few chances for survival. If one of the systems is set too "low", and fails consistently too soon, natural selection will tend to increase the level at which the system is set. If persons prone to early cancer have less offspring or less opportunity to rear them successfully, their genes will disappear. But conversely, if one of the systems is set too high, and would never fail during a normal lifetime, natural selection will tune it down. The saved resources are, in terms of natural selection, better used to boost fitness. The optimal balance between spending "enough" and spending "too much" in survival is not very sharp. ${ }^{21}$ Selection pushes survival to an optimum, but the pressure is weaker the more this optimum is approached. This allows for 
considerable variance of senescence rates. Not all people age at the same rate, and not all systems of an individual deteriorate at the same rate.

\section{The future of death}

As mentioned in the introduction, estimates of the future size of the population of elderly in the foreseeable future are nearly entirely determined by their survival. Figure 2 shows the stationary life table populations of women of two periods, 1950-54 (age standardised mortality $0.0104 / y$, life expectancy 73 years), 1985-89 (age standardised mortality $0.0062 / y$, life expectancy 80 years) and of a hypothetical period with a life expectancy of 85 year (age standardised mortality $0.0038 / y$ ). When the mortality would decline at the same (age specific) rate as between 1950-54 and 198589, this hypothetical life expectancy and mortality would occur in the period 2020-24. The stationary life table population assumes that all birth and death rates remain constant at the level of a certain period. In 1950-54, when the life expectancy was 73 years, $6.6 \%$ of the life table population was over 75 years and $1.2 \%$ over 85 years old. In $1985-89$, at a life expectancy of 80 years, $10.5 \%$ was over 75 and $3.1 \%$ over 85 . In $2020-24$, at a projected life expectancy of 85 years, an estimated $14.0 \%$ would be over 75 and $5.3 \%$ over 85 . In the Netherlands in 1994, the population of 75 and older comprised $5.5 \%$ of the population; this fraction is relatively low as a consequence of the large baby boom cohort that occurred after the second world war. However, these 5.5\% consumed $28.8 \%$ of all health care costs. ${ }^{24}$ In 2020 the survivors of the baby boom cohorts will start reaching 75 years, their ultimate size being determined by the mortality decline in elderly populations, as mortality among the young and adult is already very low. To be valid, any prediction of further declines in death rates rates should therefore involve a theory about senescence.

Based on evolutionary theory, we can make predictions about senescent death. Death is not "programmed" by death genes, but the result of a general neglect of the genetic material at older ages, both by lack of historical selection pressure and by imperfect maintenance. Life

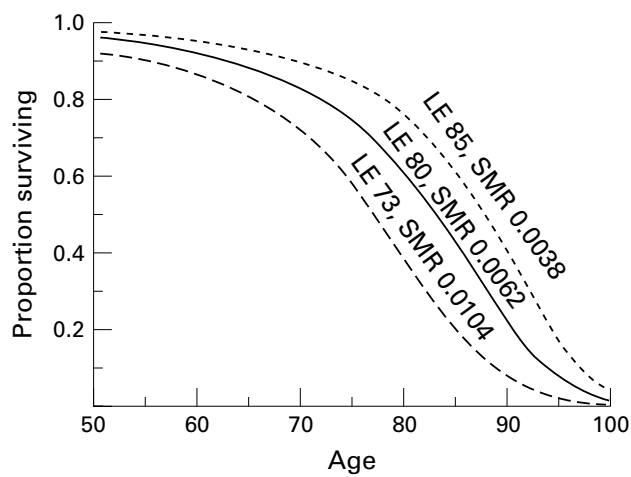

Figure 2 Survival in period life tables of Dutch women in 1950-54 (life expectancy 73 years), in 1985-89 (life expectancy 80 years) and after projecting the age specific mortality decline between 1950-1989 till 2020-24 (life expectancy 85 years).
KEY POINTS

- The key element of the evolutionary theories of aging is that after successful reproduction repair and maintenance of the genome is neglected.

- Because senescence is a consequence of general neglect, many genes and more processes are involved in the decay of the organism.

- Major breakthroughs in the reduction of mortality are unlikely, and future gains in life expectancy will be limited.

- Non-fatal and fatal diseases of old age have been equally timed by the same forces of natural selection.

- Delay of death by fatal diseases will result in the emergence of non-fatal diseases in the gained life years.

span is not fixed by "hard" programmed limits, but by "soft" probabilistic limits, a result of genetic variance and stochastic accumulation of damage. ${ }^{25}$ Major breakthroughs in "genetic engineering" of senescent mortality are very unlikely, as the number of genes involving maintenance at multiple levels is large and the potential for synergy immense. ${ }^{26}$ Opportunities for slowing the rate of senescence are to be sought in decreasing the rate of accumulation of damage, which is identical to a familiar concept to public health practitioners and epidemiologists: diminishing exposure to risk factors.

The question how much mortality reduction can be obtained by further risk factor reductions is not without answers. With the notable exception of smoking, ${ }^{27}$ simple risk factor models building on classic epidemiological techniques show but modest extensions of life expectancy by risk factor reduction, in the order of magnitude of one to a few years. ${ }^{28}{ }^{29}$ More complex multivariate models, using longitudinal data of the Framingham Heart Study, arrived at similar results. ${ }^{30}$ Predictions of "natural" life expectancies of more than 95 years and life spans of over 130 years are based on few and hard to verify observations of extinct cohorts born before 1880 and many assumptions about the "tail" of the distribution of deaths at ages above $110 .^{31}$ The probabilistic nature of the end of life, predicted by evolutionary theory, foresees a long tail of scarce survivors reaching extreme old age, but the population life expectancy is little sensitive to these small numbers.

Another approach to the problem of an uncertain future is to study the recent past, and extrapolate the changes needed to reach a certain life expectancy. ${ }^{32}$ Figure 1 showed the evolution of mortality in the 20th century by age (since 1900), figure 3 by cause of death (since 1950) in the Netherlands.

During the first half of the century, mortality declined predominantly during childhood and adulthood of both men and women, the changes in middle age being more modest. In the third quarter of the century, the difference between men and women is astonishing. Men 


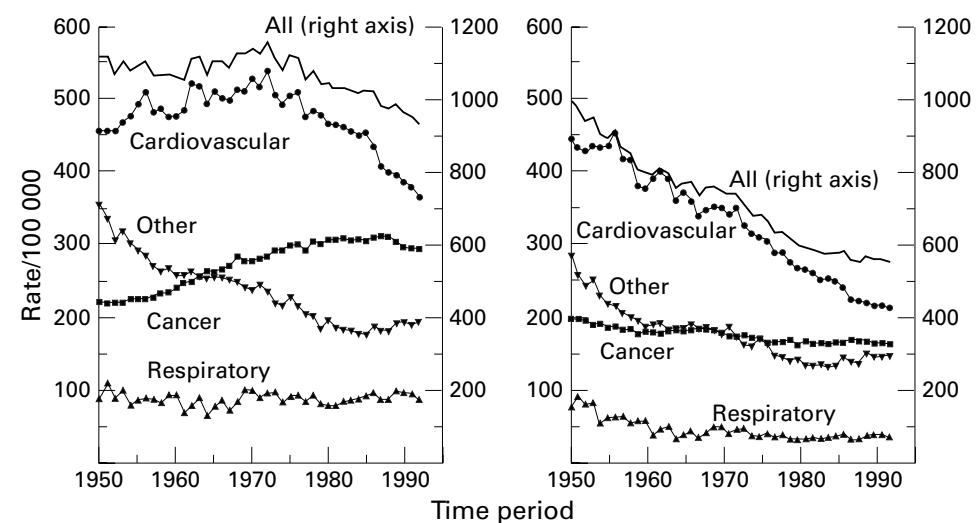

Figure 3 Death rates by sex, time period, and cause of death since 1950.

experienced increasing cardiovascular disease and cancer mortality, caused by coronary heart disease and smoking induced respiratory cancers, while among women death rates decreased from all causes. The most recent period shows again striking changes in the sex differences, but now in opposite directions. Among men, cardiovascular mortality is going down rapidly, and cancer mortality seems to have reached its peak, and starts declining now. But among women, the mortality decline is leveling off since 1980; from 1950 till 1980, age standardised mortality decreased by $1.5 \%$ per year, from 1980 till 1992 by $0.6 \%$ per year. The decrease in cardiovascular mortality slowed down. ${ }^{33}$ Cancer and respiratory disease mortality have been stagnating for a long period, and all other causes are increasing, as among men. To increase the actual life expectancy among women from 80 (80.3 years in 1994) to 85 years, all cardiovascular mortality (the only declining cause of death since 1980) has to be eradicated, or alternatively the present downward trend in mortality from all causes (an annual decline of $0.6 \%$ ) has to persist for the next 85 years.

Obviously, the recent mortality experience of Dutch women does not necessarily mirror the experience of all women of the developed world. Indeed, one study, reconstructing mortality and census counts of four racial/ethnic populations in the USA, showed that female immigrants of Asian/Pacific origin have reached a life expectancy of even more than 85 years. ${ }^{34}$ However, migrant populations are a healthy selection of the population of origin, even more so because USA immigration laws only allowed the highly educated and healthy. Secondly, moribund immigrants may return to their country of origin to die, biasing death counts. Thirdly, exaggeration of age is prevalent in most human societies; the majority of Asian migrants are foreign born, and their exact birth year is not known. ${ }^{35}{ }^{36}$ Fourthly, the actual period life table is the result of the low mortality hazard of modern time, applied to the selected survivors of past (higher) mortality. An earlier demographic transition ${ }^{37}$ and a lower historical mortality might explain the stagnating increase of life expectancy, also observed in other highly developed countries such as the Scandinavian countries. ${ }^{38}$ Higher (period) life expectancies are possible in societies moving more rapidly through the epidemiological transition, but only for a while. As the birth cohorts exposed to the high pretransitional death rates die out, the high mortality selection early in life will disappear.

The recent mortality experience of elderly in 27 developed countries showed a steady and unprecedented decline between the 1960s and 1980 s. $^{36}$ However, this mortality decline was observed in cohorts of survivors exposed to the high child mortality in the 19th century and mostly before reaching life expectancies of 80 and higher. The (relative) mortality decline, particularly among women, tapered off with age, as expected when the end of life is programmed by a "soft" probabilistic limit. ${ }^{25}$

The life expectancy of 85 years for Dutch women in 2020-24 (fig 2) was reached by projecting this historically steep mortality decline between 1950-54 and 1985-89 among women, and ignored largely the levelling off in the most recent period. If we project the period 1985-1994, it will take nearly a century before life expectancy of Dutch women reaches 85 years. So for the foreseeable future (female) life expectancies above 85 seem unlikely in the Netherlands. In selected populations, and in populations moving rapidly through the demographic transition, higher period life expectancies are possible at the end of the transition, but only for a while. While among hunter gatherers grandparents are useful to their genetic offspring because of the prolonged period of juvenile dependence, ${ }^{39}$ the maintenance schedule of Homo sapiens does not foresee greatgrandparents.

\section{Compressing disability, expanding health care needs?}

The mortality trends from the recent past among Dutch women are insufficient to reach a life expectancy of 85 years within a half century. However, even moderate increases in life expectancy will sharply increase numbers of elderly, as we showed previously. The next question is how healthy or disabled these future populations will be.

The question if and how senescent disability among these elderly will change depends basically on the equilibrium of three forces. The first force slows the rate of senescence, decreases incidence, and "compresses" senescence until old age. The second force decreases the mortality hazard, increases disease duration, and expands senescence. Disability and death at old age are timed by the same process, and successfully postponing death from one cause will increase disability from other causes. And the often forgotten third force "compresses" morbidity, not by reducing the numbers but by reducing the severity of disease: by successfully preventing, treating or palliating disability. There is consequently a paradoxical relation between disability and health care need. Actual disability is the disability not prevented and not palliated. One of Fries' prime examples of compression of disease, stroke, has been brought about in part by health care, namely treatment of hypertension, which costs 
$1.3 \%$ of the total Dutch health care budget. $^{24} 4041$ Historically, it is reasonable to assume that the epidemiological transition causes both decreasing mortality and decreasing disability as most of the transition is caused by prevention of infectious diseases. ${ }^{42}{ }^{43}$ However, in the fourth phase of the transition, the age of delayed degenerative disease, ${ }^{44}$ health care is one of the prime forces of change. The effects of health care on disability are mixed: health care increases disability by delaying (cardiovascular) death, decreases severity by palliating disease symptoms, and prevents disability by treating risk factors such as diabetes mellitus, hypertension, and cholesterol. So it is no surprise that disability free life expectancy is increasing and age adjusted disability trends in elderly are still decreasing in the fourth phase of the transition. ${ }^{45}$ However, if life expectancy increases further, senescent diseases, timed by the same evolutionary forces as senescent death, are uncovered. Health care needs will increase to reduce the ensuing disability. If and how disability will compress, will depend mainly on the effectivity of that health care, but there is little doubt that health care needs will increase.

This paper was funded by the Ministry of Health, Welfare and Cultural Affairs of the Netherlands and the Netherlands Organization for Scientific Research.

We wish to acknowledge Sake De Vlas, biologist, Kees Van Bezooyen, gerontologist, Ewout Steyerberg, medical decision making, and Karin Meeter, cardiologist, for helpful comments on previous drafts

1 Bennet N, Olshansky S. Forecasting US age structure and the future of social security: the impact of adjustments to official mortality schedules. Population and Development Review 1996;22:703-27.

2 Jorm AF, Korten AE, Jacomb PA. Projected increases in the number of dementia cases for 29 developed countries: application of a new method for making projections. Acta Psychiatr Scand 1988;78:493-500.

3 Schneider EL, Guralnik JM. The aging of America. Impact Schneider EL, Guralnik JM. The aging of America.
on health care costs. $\mathscr{F} A M A$ 1990;263:2335-40.

4 Bonneux L, Barendregt JJ, Meeter K, Bonsel GJ, van der Maas PJ. Estimating clinical morbidity due to ischemic Maas PJ. Estimating clinical morbidity due to ischemic heart disease and congestive heart failure: the futur

5 Carnes BA, Olshansky SJ, Grahn D. Continuing the search for a law of mortality. Population and Development reviez 1996;22:231-64

6 Medawar PB. An unsolved problem in biology. London: Lewis, 1952.

7 Kirkwood TBL. Comparative and evolutionary aspects of longevity. In: Finch CE, Schneider EL, eds. Handbook of the biology of aging. New York: Van Nostrand Reinhold, 1985: $27-44$.

8 Kirkwood TB. Comparative life spans of species: why do species have the life spans they do? Am $\mathcal{F}$ Clin Nutr 1992;55:1191-5S.

9 Kirkwood TB, Rose MR. Evolution of senescence: late survival sacrificed for reproduction. Philos Trans $R$ Soc Lond B Biol Sci 1991;332:15-24.

10 Jazwinski SM. Longevity, genes and aging. Science 1996; 273:54-9.

11 Dawkins R. The selfish gene (new edition). New York: Oxford University Press, 1989.

12 Darwin C. On the origin of species. London: John Murray, 1859 .
13 Dawkins R. The extended phenotype. New York: Oxford University Press, 1989.

14 Dawkins R. River out of Eden. London: Phoenix, Orion Books, 1995.

15 Williams GC. Pleiotropy, natural selection and the evolution of scenescence. Evolution 1957;22:398-411.

16 Kirkwood TB. Evolution of ageing. Nature 1977;270:301-4.

17 Parker GA, Maynard-Smith J. Optimality theory in evolutionary biology. Nature 1990;348:27-33.

18 Partridge L, Barton NH. Optimality, mutation and the evolution of ageing. Nature 1993;362:305-11.

19 Sacher GA. Mammalian life histories: their evolution and molecular-genetic mechanisms. Adv Pathobiol 1980;7:2142

20 Harvey PH, Clutton-Brock TH. Life history variation in primates. Evolution 1985;39:559-81.

21 Kirkwood TB, Franceschi C. Is aging as complex as it would appear? New perspectives in aging research. Ann N Y Acad Sci 1992;663:412-17.

22 Weindruch R. Caloric restriction and aging. Sci Am 1996;274:46-52.

23 Sohal RS, Weindruch R. Oxidative stress, caloric restriction, and aging. Science 1996;273:59-63.

24 Meerding WJ, Bonneux L, Polder JJ, et al. Demographic and epidemiological determinants of healthcare costs in the Netherlands: costs of illness study. BMF 1988;317:111-15.

25 Manton KG, Tolley HD. Rectangularization of the survival curve. Implications of an ill posed question. $\mathcal{7}$ Aging Health 1991;3:172-93.

26 Kirkwood T. How can we live forever? BMf 1996;313:1571.

27 Peto R, Lopez AD, Boreham J, Thun M, Heath C Jr, Doll R. Mortality from smoking worldwide. Br Med Bull 1996;52: $12-21$.

28 Gunning-Schepers L. The health benefits of prevention: a simulation approach. F Health Policy 1989;12/1-2:93-129.

29 Tsevat J, Weinstein M, Williams L, Tosteston A, Goldman L. Expected gains in life expectancy from various coronary heart disease risk factor modifications. Circulation 1991;83. $1194-201$.

30 Manton KG, Stallard E. Chronic disease modelling. London, England: Charles Griffins, 1988.

31 Manton KG, Stallard E. Longevity in the united states: age and sex-specific evidence on life span limits from mortality patterns 1960-1990. F Gerontol A Biol Sci Med Sci 1996;51: B362-75.

32 Olshansky S, Carnes B, Cassel C. In search of Methuselah: estimating the upper limits to human longevity. Science 1990;250:634-40.

33 Bonneux L, Looman CW, Barendregt JJ, Van der Maas PJ. Regression analysis of recent changes in cardiovascular mortality and morbidity in the Netherlands. BMF 1997; 314:789-92.

34 Hahn RA, Eberhardt S. Life expectancy in four U.S. racial/ ethnic populations: 1990. Epidemiology 1995;6:350-5.

35 Rosenwaike I. A note on new estimates of the mortality of the extreme aged. Demography 1981;18:257-66.

36 Kannisto V, Lauritsen J, Thatcher A, Vaupel J. Reductions in mortality at advanced ages: Several decades of evidence from 27 countries. Population and Development Review 1994;20:793-810

37 Omran AR. The epidemiologic transition: a theory of the epidemiology of population change. Milbank Memorial Fund Quarterly 1971;49:509-38.

38 Van Hoorn WD. Mortality: trends, backgrounds and forecast. Monthly population statistics. Voorburg Heerlen: Statistics Netherlands, 1997:10-15.

39 Peccei JS. A hypothesis for the origin and evolution of menopause. Maturitas 1995;21:83-9.

40 Fries JF. Aging, natural death, and the compression of morbidity. $N$ Engl f Med 1980;303:130-5.

41 Bonita R. Epidemiology of stroke. Lancet 1992;339:342-4.

42 Murray CJL, Lopez AD. Regional patterns of disability free life expectancy and disability adjusted life expectancy. The global burden of disease study. Lancet 1997;349:1347-52.

43 Barendregt JJ, Nusselder WJ, Bonneux L. Global burden of disease. [Letter]. Lancet 1997;350:142-3.

44 Olshansky SJ, Ault AB. The fourth stage of the epidemiologic transition: the age of delayed degenerative disease. Milbank Memorial Fund Quarterly 1986;49:355-91.

45 Manton KG, Corder L, Stallard E. Chronic disability trends in elderly United States populations: 1982-1994. Proc Natl Acad Sci U S A 1997;94:2593-8. 